\title{
End-of-Life Treatment Strategies for Flat Screen televisions: A Case Study
}

\author{
J. R. Peeters ${ }^{1}$, P. Vanegas ${ }^{1,2}$, W. Dewulf ${ }^{3}$, J. R. Duflou ${ }^{1}$ \\ ${ }^{1}$ Department of Mechanical Engineering, Katholieke Universiteit Leuven, Belgium \\ ${ }^{2}$ University of Cuenca, Ecuador \\ ${ }^{3}$ Group T-International University College Leuven, K.U.Leuven Association, Belgium
}

\begin{abstract}
The European recycling directive increases the pressure to improve the recycling processes for the rapidly increasing number of End-of-Life (EoL) flat screen televisions. Based on a case study an estimation of the expected economic and environmental benefits of the availability of product information for different EoL treatment strategies is provided. This case study demonstrates that pre-processing operations, such as dismantling, product sorting and clustering, allow to increase the economic viability and sustainability of recycling flat screen televisions. One of the main challenges for implementing pre-processing operations in an industrial setting is that these operations require the ability of product identification and specific product information, such as product structure and material composition. To allow such an exchange of key information, a holistic life cycle approach is required, in which all different actors in the lifecycle are involved, as is achieved in the Flemish PRIME project.
\end{abstract}

Keywords:

Liquid Crystal Display (LCD), Plasma flat screen TVs, Product Clustering, Recycling

\section{INTRODUCTION}

The costs and environmental impact caused by the End-ofLife (EoL) treatment of Waste of Electric and Electronic Equipment (WEEE) strongly depend on the adopted recycling strategies [1]. Therefore, these costs can be influenced by future technologic developments. There are multiple reasons why the optimization of the current recycling processes or the development of alternative EoL treatment strategies for WEEE is required. Firstly, there is a high cost for collecting and recycling WEEE, which cannot be covered by the revenues from the recovered materials. This total negative profit for recycling WEEE in EU27 is estimated to raise about $16 \%$ compared to 2005 , increasing to 1.97 billion in 2011 [1]. Secondly, the European WEEE directive and the upcoming recast of this directive are another important reason for recyclers to optimize their recycling processes. The quotas of this recast will range from 50 to $70 \%$ with respect to recycling and a recovery rate of 70 to $80 \%$ depending on the product category [2]. According to the current WEEE Directive recycling means the reprocessing of a waste material for the original or other purposes, and recovery means the use of combustible waste as a means of generating energy through direct incineration, which currently is a common treatment for polymeric materials [3]. Achieving the recycling rates of the upcoming recast will be difficult with the current EoL treatment strategies, as plastics make up about $20 \%$ by weight of WEEE [4]. According to recent studies, Liquid Crystal Display (LCD) televisions (TVs) even contain about $30 \%$ polymers $[1,5]$. Prior research also indicates that recycling polymers can reduce the environmental impact with up to $40 \%$ compared to incinerating polymers with energy recovery [6]. Besides polymers, different products in WEEE, such as flat screen TVs, also contain precious metals with a high economic value and a considerable environmental impact when not reclaimed [7]. For this reason, it is imperative to develop EoL treatment strategies which include recycling of polymeric materials and precious metals $[8,9]$.

\section{CURRENT END OF LIFE STRATEGIES FOR CRT AND FLAT SCREEN TVS}

The current treatment strategies in Europe for Cathode Ray Tube (CRT) and flat screen TVs mainly involve direct shredding and to a minor extend (partial) manual disassembly. According to Huisman et al. [1] none of the currently adopted EoL treatment strategies for WEEE is economically viable. The main reasons for this low return, according to Huisman [1], are the high collection, transportation and treatment costs, which cannot be covered by the revenues from the recovered materials.

For the EoL treatment of CRT TVs manual disassembly is no longer required, as re-application of CRT glass is no longer possible [10]. Therefore, the current treatment of CRT TVs is comparable to the direct shredding strategy as applied for the treatment of Small Household Appliances (SHA), for which Huisman et al. indicate an EoL treatment cost of 259 euro per tonne. For the values of recovered materials from CRT TVs a wide range of data are available. Therefore, an update of the value of recovered materials from CRT TVs is given in Table 1 based on the average CRT TV material content as stated by Huisman et al. [1, 11] and Lamberet et al. [12]. These data indicate that nearly all treatment costs, as calculated by Huisman et al., can be covered by the revenues of recovered materials. Furthermore, the recycling rate required by the European WEEE directive is achieved for the EoL treatment of CRT TVs. The main reason for this high recycling rate is the fact that the significantly large fraction of CRT glass is used in the building industry, which is still counted as recycling according to the WEEE directive. 
Table 1: Value of recovered materials and recycling rates according to the WEEE directive for a CRT TV

\begin{tabular}{lcccc}
\hline \multicolumn{1}{c}{ Material custom name } & $\begin{array}{c}\text { Value of recovered material } \\
{[1,5,13,14](€ / \text { tonne) }}\end{array}$ & $\begin{array}{c}\text { Material recovery } \\
\text { efficiency [5] (\%) }\end{array}$ & $\begin{array}{c}\text { CRT TV weight } \\
{[11](\%)}\end{array}$ & $\begin{array}{c}\text { CRT TV weight } \\
{[12](\%)}\end{array}$ \\
\hline Cu (Copper) & 5694 & $99,0 \%$ & 3 & 5 \\
Plastics send to incineration & -160 & $100,0 \%$ & 21 & 34 \\
Metals: Ferrous based & 220 & $75,0 \%$ & 17 & 8 \\
Metals: Aluminum based & 2060 & $88,0 \%$ & 3 & 2 \\
CRT Glass & -55 & $99,0 \%$ & 55 & 47 \\
PCB \& Rest fraction & -160 & $100,0 \%$ & 1 & 5 \\
\hline Value of recovered materials per tonne of CRT TVs (€/tonne) & & $\mathbf{2 1 3}$ & $\mathbf{2 3 8}$ \\
Recycling rate according to the WEEE directive & & $\mathbf{7 3 \%}$ & $\mathbf{5 8 \%}$ \\
\hline
\end{tabular}

Compared to the EoL treatment of CRT TVs, the EoL treatment cost is expected to significantly increase for flat screen TVs which use Cold Cathode Fluorescent Lamps (CCFLs) as backlight [1]. This increase in treatment cost is due to the required and costly additional process for the removal of toxic mercury vapors from the CCFLs. Furthermore, flat screen TVs contain substantially less copper, aluminum and steel compared to CRT TVs. Therefore, the costs of the EoL treatment of flat screen televisions can only be covered by recycling more precious metals and polymers in a cost efficient way.. Such an improvement can be obtained by implementing advanced post-shredder separation processes. For a direct shredder strategy with advanced post-processing, different technologies have recently been developed to separate shredder output based on optical properties of the different materials. However, prior projects demonstrate that the main challenges for implementing such a strategy are the high investment costs for the optical separation equipment and the low separation efficiency of the optical separation processes $[5,15]$. Furthermore, an additional purification step is required for polymers after optical separation, since possible metal contamination can impede their reuse. Consequently, still a relatively high gate fee would be required to make this EoL treatment economically viable for flat screen TVs. For this reason, such a strategy with advanced post-shredder separation involves a high investment risk, while new technologies or alternative EoL strategies can still emerge.

Another strategy to increase the amount of recovered materials is to manually disassemble EoL TVs. For manual disassembly the treatment cost is mainly related to the amount of time required to disassemble a flat screen television and the labor wages. According to Salhofer et Al. disassembling a flat panel display requires 24 minutes on average, which results in a dismantling cost of 477 euro per tonne when considering an hourly rate of 18 euro [13]. Because of high labor costs in Europe, manual disassembly is generally characterized by a low to negative profitability [16]. Furthermore, there is a health risk when LCD TVs are not carefully handled and disassembled, since these products often contain fragile CCF backlight lamps with toxic mercury vapors.

\section{PRODUCT CLUSTERING AS AN END OF LIFE STRATEGY: A CASE STUDY}

The low separation efficiency of optical sorting processes for polymers is mainly related to difficulties with the identification of polymer additives of shredded materials at high throughputs [8]. As a result, polymers can currently not be separated with high efficiency on the polymer additives, such as flame retardants. Consequently, it is difficult to separate plastics with banned flame retardants from non banned flame retardants with the current separation techniques. Therefore, a substantial amount of plastics cannot be recovered with the current EoL treatment strategies. Nevertheless, on average about $25 \%$ of all WEEE plastics contain flame retardants [4], depending on the product categories and product brands. Furthermore, a recent study shows that for housings from EoL TVs and monitors the amount of encountered bromide based flame retardants is decreasing [17]. Nowadays, about $50 \%$ of all flame retardants in WEEE are expected to be phosphor based, which is authorized for re-use by European legislation. However, still about $40 \%$ of all bromide flame retardants, used in EoL television and monitor housings, are nowadays banned by the European legislation [8]. Recent studies show that the presence of commonly used flame retardants is not a technical obstacle for polymer recycling. In some cases these flame retardants appear to even improve the performance and feasibility of the recycling processes [18]. Therefore, it is advisable to cluster flat screen TVs before shredding based on the additives used in the plastics in order to allow the recovery of polymers with non-banned flame retardants.

In the case study presented in this paper, the potential revenues of recovered materials and the potential recycling rate in accordance with the European WEEE directive are calculated for different EoL treatment strategies, as shown in Table 2. A comparison is made between an EoL strategy with clustering and a direct shredder strategy with and without advanced post processing, and a full manual disassembly strategy. Furthermore, the material contents of both a Philips 42" LCD and a Philips 50" plasma television are analyzed. The current market is mainly dominated by LCD televisions (90\%). However, plasma televisions are also analyzed within this case study, as they are expected to represent a significant share of the EoL flat screen TVs in the coming years, as mainly plasma televisions were sold before 2005 [1]. 
Table 2: Value of recovered materials and recycling rates according to the WEEE directive for a Philips LCD television for different EoL treatment strategies

\begin{tabular}{|c|c|c|c|c|c|c|c|}
\hline Material Custom Name & Weight & $\begin{array}{c}\text { Weight / } \\
\text { TV }\end{array}$ & $\begin{array}{l}\text { Value of } \\
\text { recovered } \\
\text { material }\end{array}$ & $\begin{array}{c}\text { Direct } \\
\text { shedder } \\
\text { strategy }\end{array}$ & $\begin{array}{c}\text { Direct shedder } \\
\text { + advanced } \\
\text { post- } \\
\text { processing } \\
\text { strategy }\end{array}$ & $\begin{array}{c}\text { Manual } \\
\text { disassem } \\
\text { bly } \\
\text { strategy }\end{array}$ & $\begin{array}{c}\text { Clustering + } \\
\text { shredder + } \\
\text { advanced post- } \\
\text { processing } \\
\text { strategy }\end{array}$ \\
\hline & $(\mathrm{g} / \mathrm{TV})$ & $(\%)$ & (euro) & $(\%)$ & $(\%)$ & $(\%)$ & $(\%)$ \\
\hline Polymers (incineration) & 9976 & $34 \%$ & -160 & 100 & 88 & 6 & 27 \\
\hline Thermoplastics & 330 & $1 \%$ & 400 & 0 & 0 & 0 & 0 \\
\hline PET & 1054 & $4 \%$ & 660 & 0 & 50 & 100 & 50 \\
\hline PMMA & 1170 & $4 \%$ & 2920 & 0 & 50 & 100 & 50 \\
\hline$A B S+P C$ & 111 & $0 \%$ & 2840 & 0 & 50 & 0 & 50 \\
\hline$A B S+P C+F R 40$ & 4647 & $16 \%$ & 1370 & 0 & 0 & 99 & 90 \\
\hline$P C+F R 40$ & 2192 & $7 \%$ & 1370 & 0 & 0 & 97 & 90 \\
\hline $\mathrm{PC}+\mathrm{GF} 10$ & 472 & $2 \%$ & 300 & 0 & 0 & 100 & 0 \\
\hline Glass LCD & 2760 & $9 \%$ & 50 & 0 & 0 & 100 & 0 \\
\hline Metals: Ferro based & 13834 & $47 \%$ & 220 & 75 & 75 & 75 & 75 \\
\hline Metals: Aluminum based & 795 & $3 \%$ & 2060 & 88 & 88 & 88 & 88 \\
\hline \multicolumn{4}{|c|}{ Value of recovered materials / Tonne of televisions $(€)$} & 72 & 154 & 586 & 474 \\
\hline \multicolumn{4}{|c|}{ Recycling rate according to the WEEE directive } & $38 \%$ & $42 \%$ & $79 \%$ & $63 \%$ \\
\hline
\end{tabular}

Table 3 Value of recovered materials and recycling rates according to the WEEE directive for a Philips Plasma television for different EoL treatment strategies

\begin{tabular}{|c|c|c|c|c|c|c|c|}
\hline Material Custom Name & Weight & $\begin{array}{c}\text { Weight / } \\
\text { TV }\end{array}$ & $\begin{array}{l}\text { Value of } \\
\text { recovered } \\
\text { material }\end{array}$ & $\begin{array}{l}\text { Direct } \\
\text { shedder } \\
\text { strategy }\end{array}$ & $\begin{array}{l}\text { Direct shedder } \\
\text { + advanced } \\
\text { post- } \\
\text { processing } \\
\text { strategy } \\
\end{array}$ & $\begin{array}{c}\text { Manual } \\
\text { disassembly } \\
\text { strategy }\end{array}$ & $\begin{array}{l}\text { Clustering + } \\
\text { shredder + } \\
\text { advanced post- } \\
\text { processing } \\
\text { strategy }\end{array}$ \\
\hline & $(\mathrm{g} / \mathrm{TV})$ & $(\%)$ & (euro) & $(\%)$ & $(\%)$ & $(\%)$ & $(\%)$ \\
\hline Polymers (incineration) & 5396 & $9 \%$ & -160 & 100 & 99 & 15 & 36 \\
\hline Thermoplastics & 820 & $2 \%$ & 400 & 0 & 0 & 0 & 0 \\
\hline ABS & 160 & $0 \%$ & 1540 & 0 & 50 & 100 & 50 \\
\hline$A B S+P C+F R 40$ & 3756 & $8 \%$ & 1370 & 0 & 0 & 100 & 90 \\
\hline $\mathrm{PC}+\mathrm{GF} 10$ & 660 & $1 \%$ & 300 & 0 & 0 & 100 & 0 \\
\hline Glass & 18215 & $37 \%$ & -55 & 90 & 90 & 100 & 90 \\
\hline Metals: Ferro based & 13005 & $26 \%$ & 220 & 75 & 75 & 75 & 75 \\
\hline Metals: Aluminum based & 5700 & $11 \%$ & 2060 & 88 & 88 & 88 & 88 \\
\hline \multicolumn{4}{|c|}{ Value of recovered materials / Tonne of televisions $(€)$} & 365 & 369 & 576 & 545 \\
\hline \multicolumn{4}{|c|}{ Recycling rate according to the WEEE directive } & $63 \%$ & $63 \%$ & $75 \%$ & $70 \%$ \\
\hline
\end{tabular}

The material recovery rates for the ferrous metals and the aluminum, used in the calculations, are based on the estimated efficiency of magnetic and eddy current separation processes for shredded material from flat screen TVs [5]. The recovery rates for the advanced post processing processes are based on the estimated separation efficiency of a Near InfraRed (NIR) TITECH device for the separation of Polystyrene (PS) and Acrylonitrile Butadiene Styrene (ABS) from mixed WEEE polymers [15]. The low separation efficiency for NIR separation processes is also due to problems with blackness detection, which has a significant influence, as television housings are dominated by black plastics [17]. Therefore, further research is required to determine more accurate recovery rates for Polymethylmethacrylate (PMMA) and Polyethylene Terephtalate (PET). These polymers are mainly white or transparent, since they are commonly used to diffuse the backlight in LCD TVs. Consequently, the recovery rate is expected to increase, since NIR separation processes do not have problems due to blackness detection for these polymers. Nevertheless, the main polymer fraction with flame retardants cannot be recovered with this strategy, since optical separation of polymers based on their flame retardants is currently not feasible at high material throughputs. For the manual disassembly strategy the recovery rates are calculated assuming that all big and easily identifiable components are disassembled and recycled.

All values of recovered materials used for this case study are based on estimates from prior studies. The values of recovered materials differ significantly between sources, since they are generally incinerated with energy recovery and not recycled $[1,5,13,15]$. For this case study, rather optimistic values of recovered materials in Europe, as proposed by Huisman et al., are used [1]. However, to receive these values for recovered material a steady supply of polymers with an assured quality should be achieved. For 
polymers sent to incineration with energy recovery a cost of 160 euro per tonne is taken into account, based on data from Salhofer et al. [13]. Both for the LC display and for the glass of the plasma television the values of the recovered materials are based on data from Cryan et al. [5]. Only limited data are available about the precious metal content and value of PCBs from flat screen TVs. Therefore, the PCBs, as well as the cables connected to these PCBs, are not taken into account for the calculations in this case study. Nevertheless, the recovery of precious metals from $\mathrm{PCBs}$ can contribute to a more economically viable EoL treatment of flat screen TVs, as discussed further in the next section.

\section{EOL TREATMENT STRATEGIES FOR LCD AND PLASMA TVS}

The case study, presented in this paper, indicates that there is a significant difference in material content between plasma and LCD TVs. The main difference is that LCD TVs contain a higher amount and more types of polymers, while plasma TVs contain a substantially higher amount of glass. Furthermore, compared to CRT TVs, LCD TVs contain less ferrous metals and aluminum. As a result, for an EoL treatment strategy with direct shredding and commonly used separation processes, such as magnetic separation and eddy current separation, only a low value can be recovered from LCD TVs. For plasma TVs a considerably higher value can be recovered with this EoL treatment strategy. Compared to the EoL treatment of CRT TVs a significantly lower value is recovered from LCD TVs. Also a much lower recycling rate is achievable for LCD TVs than required by the European WEEE directive. For plasma TVs, on the other hand, a relatively high recycling rate is achievable, since the large glass fraction can be recycled by the building industry. An EoL treatment strategy with advanced post-shredder separation processes, such as optical polymer separation, is mainly promising for the EoL treatment of LCD TVs, which contain a higher amount of polymers. For plasma TVs this EoL treatment strategy only comports low improvements, since most polymers of the analyzed plasma television are from the product housing and contain flame retardants. Although an increase in value of the recovered material can be achieved by means of advanced post-shredder techniques, only a low recycling rate is achieved for EoL LCD TVs.

Compared to other EoL treatment strategies, an EoL strategy with manual disassembly can significantly increase the value of recovered materials, as well as the percentage of recycled materials. Assuming the availability of detailed information about the material content, manual disassembly can be assumed economically viable for LCD TVs. Based on this case study. the value of the recovered material can cover the dismantling cost of 477 euro per tonne of flat screen TVs, as calculated by Salfhofer et al. [13]. However, in order to receive the material prices used in the case study for recovered materials, a steady supply of recovered polymers with an assured quality should be achieved. Furthermore, detailed information about the material content is required. Only with information about the polymer additives of every component a manual separation of polymers based on their flame retardant is possible, since the used type of flame retardant is generally not indicated on the components.
The case study also indicates that an EoL treatment strategy with clustering based on product information allows to significantly increase the value of recovered materials. This improvement is achieved by processing a cluster of products without banned flame retardants separately, which allows separating and recycling polymers with flame retardants. The recovery rates for these processes are based on those of density based separation processes for plastics without flame retardants, as presented by Gent et al. [19]. However, future research is required to determine more accurate recovery rates for density based separation processes for plastics with flame retardants. Furthermore, by processing products which mainly contain compatible polymers for recycling, such as ABS and Polycarbonate (PC), no further separation of these plastics is required. As a result, such a strategy allows recycling a significantly higher amount of materials for LCD TVs compared to strategies with unsorted shredding. Another advantages of an EoL treatment strategy which involves product clustering based on hazardous substances, is that certain separation processes can be omitted. For example a first clustering can be done based on the adopted flat screen television technology, as the material content strongly depends on the adopted technology. In this way, when clustering only plasma TVs, the process of mercury removal can be avoided.

A strategy which involves clustering can furthermore make the recovery of Printed Circuit Boards (PCBs) from flat screen TVs economically feasible. Based on the average material content of an LCD television, as described by Huisman et al. [1], and values of recovered PCBs, as used by Keller [1, 20], the PCBs of LCD televisions have an economic value of about 56 euro per tonne of TVs. Nevertheless, only about a quarter of the precious metals typically found in PCB components generally ends up in the fraction for precious metals recovery when mixed WEEE is mechanically processed [21]. The efficiency of the recovery of PCBs can be improved by adopting pre-shredder processes according to Meskers et al. [22]. Hence, a clustering strategy can improve the recovery of precious metals, as it allows differentiating the processes to recover PCBs applied for different clusters. For example, when destructively opening the housing of flat screen TVs the recovery rate of precious metals can be expected to improve. When considering flat screen TVs similar to personal computers (PCs), a recovery of about $75 \%$ of the PCBs by means of manual picking can be assumed [22]. Furthermore, manual disassembly can allow a recovery of more than $95 \%$ of $\mathrm{PCBs}$ for the EoL treatment of PCs [22]. Hence, manual disassembly can become feasible for clusters of flat screen TVs with higher value PCBs and/or faster accessibility to them.

\section{REQUIRED INFORMATION FOR AN OPTIMIZED EOL STRATEGY WITH CLUSTERING}

The case study shows that clustering of products based on product information can allow to significantly increase the material recovery, as well as the economic viability of the EoL treatment of flat screen TVs. However, to enable such a clustering strategy the availability of proper product information is required. Only based on relevant product information flat screen TVs can be correctly sorted in an optimal number of clusters. The desirable properties of this product information can be described by three dimensions: the level of detail of the product information, the ability of 
product identification and the product information location. Nowadays, products are already clustered during the EoL treatment based on their visually identifiable properties. For flat screen TVs such an identification can allow a first clustering, such as clustering plasma and LCD flat screen TVs. However, for further optimization of the EoL treatment of flat screen TVs, more detailed product information is required. For example, to improve polymer recycling and avoid pollution with banned brominated flame retardants, detailed information about the used polymers and additives is required. To allow such a clustering based on more detailed information, more advanced product identification processes are needed. For example, bar code labels, which are commonly placed on flat screen TVs for logistic reasons, can sometimes still be used to identify the product model at the EoL of the product. The product model can then be used to look up detailed product information. However, the reliability and efficiency of the identification can be improved by either applying modern identification technologies, such as Radio Frequency Identification (RFID), or by applying product recognition technologies at the EoL treatment. If product identification is possible, it does not necessarily mean that the information needs to be located at the product. Two extreme scenarios can be identified here: Information access through a data network or information integrated in the product [23]. A system which enables access to product information through a data network seems most appropriate for this application. In this way manufacturers will be able to better protect their Intellectual Property (IP) and can choose to only share product information when their products reach their EoL. Furthermore, such a system can support a business model in which the product manufacturer is able to sell product information in accordance to the surplus value it comports to the recycler [24].

To enable such an exchange of product information a holistic approach is required, where the product manufacturer is involved in the EoL treatment. Manufacturers possess a lot of valuable product information, which can allow an optimal product clustering. In the Flemish PRIME project such a collaboration between a manufacturer and recyclers is achieved through the participation of Philips, a flat screen TVs manufacturer, and two recycling companies, Van Gansewinkel and Umicore. The main goal of this project is to optimize the economical viability and sustainability of the EoL treatment of flat screen TVs. The opportunities of an EoL treatment strategy with product clustering based on product information from the manufacturer, which is presented in this paper, will be further investigated within the PRIME project.

\section{CONCLUSION}

The case study, presented in this paper, demonstrates that a higher recycling rate according to the WEEE directive and a substantial economic improvement can be reached by applying an EoL treatment strategy for flat screen TVs with product clustering based on material composition. However, to allow the implementation of such an EoL treatment strategy, a business model which includes both the flat screen manufacturer and the recycler is required. In this way the exchange of required and detailed product information for sorting EoL flat screen TVs in optimal clusters will be stimulated. To allow further optimization of the EoL treatment of flat screen TVs, a better knowledge of the product design and material content, as well as the material compatibility for different recycling processes is necessary. Only based on this information clusters of products can be optimized together with the corresponding economically and ecologically optimal EoL treatment.

\section{ACKNOWLEDGMENTS}

The authors acknowledge the Flemish Environmental Technology Platform (MIP) for funding this research. The authors also like to acknowledge all partners in this project: The Flemish Institute for Technological Research (VITO), Philips, Van Gansewinkel, Umicore, Nitto and Beco.

\section{REFERENCES}

[1] J. Huisman, et al., "2008 Review of Directive 2002/96 on Waste Electrical and Electronic Equipment (WEEE)," United Nations University2007 2008.

[2] Council-of-the-European-Union, "2008/0241 (COD) Proposal for a Directive of the European Parliament and of the Council on Waste Electrical and Electronic Equipment (WEEE) (Recast)," ed, 2011, p. 104.

[3] European-Parliament, "Directive 2002/96/EC of the European Parliament and of the Council of 27 January 2003 on Waste Electrical and Electronic Equipment (WEEE)," ed, 2003, p. 24.

[4] (2011). Waste Electrical and Electronic Equipment (WEEE). Available: http://scp.eionet.europa.eu/themes/waste

[5] J. Cryan, et al., "Demonstration of Flat Panel Display recycling technologies," WRAP2010.

[6] G. Dodbiba, et al., "The recycling of plastic wastes from discarded TV sets: comparing energy recovery with mechanical recycling in the context of life cycle assessment," Journal of Cleaner Production, vol. 16, pp. 458-470, 2008.

[7] J. Huisman, et al., "Eco-efficiency considerations on the end-of-life of consumer electronic products," Electronics Packaging Manufacturing, IEEE Transactions on, vol. 27, pp. 9-25, 2004.

[8] M. Schlummer, et al., "Characterisation of polymer fractions from waste electrical and electronic equipment (WEEE) and implications for waste management," Chemosphere, vol. 67, pp. 18661876, 2007.

[9] C. Luttropp, Eco Quality Polymers-EQP Glocalized Solutions for Sustainability in Manufacturing, 2011.

[10] J. Gregory, Supply and demand in the material recovery system for cathode ray tube glass 2009 IEEE International Symposium on Sustainable Systems and Technology, 2009. 
[11] J. Huisman, et al., "The QWERTY concept, a powerful concept for evaluating the environmental consequences of end-of-life processing of consumer electronic products," in Environmentally Conscious Design and Inverse Manufacturing, 2001. Proceedings EcoDesign 2001: Second International Symposium on, 2001, pp. 929-934.

[12] A. J. D. Lambert, Disassembly Modeling For Assembly, Maintenance, Re, 2005.

[13] S. Salhofer, et al., "Recycling of LCD Screens in Europe - State of the Art and Challenges," in Glocalized Solutions for Sustainability in Manufacturing, J. Hesselbach and C. Herrmann, Eds., ed: Springer Berlin Heidelberg, 2011, pp. 454-458.

[14] (2011). Ferrous and nonferrous news and prices. Available: http://www.ryansnotes.com/

[15] L. E. Mike Bennett, Lidia Goyos-Ball, Robin Hilder, Dr Phillip Hall, Liz Morrish, Roger Morton and Nicola Myles,, "Separation of mixed WEEE plastics," WRAP2009.

[16] J. R. Duflou, et al., "Efficiency and feasibility of product disassembly: A case-based study," CIRP Annals - Manufacturing Technology, vol. 57, pp. 583-600, 2008.

[17] M. Schlummer, "Recycling of styrene polymers from shredded screen housings containing brominated flame retardants," Journal of applied polymer science, vol. 102, p. 1262, 2006.
[18] Cefic and EFRA, "Recycling and disposal End of life of products containing flame retardants," ed: European Chemical Industry Council, 2006.

[19] M. R. Gent, "Recycling of plastic waste by density separation: prospects for optimization," Waste management \& research, vol. 27, p. 175, 2009.

[20] M. Keller, "Assesment of gold recovery processes in Bangalore, India and evaluation of an alternative recycling path for printed wiring boards: A case study," Institute for Spatial and Landscape Planning, Regional Resource Management, ETH Zurich, 2006.

[21] P. Chancerel, et al., "E-scrap metals too precious to ignore," Recycling international, vol. November, pp. 42-45, 2008.

[22] C. E. M. Meskers, et al., "Impact of pre-processing routes on precious metal recovery from PCs," presented at the EMC 2009, Innsbruck, Austria, 2009.

[23] K. A. Hribernik, Intelligent Products to Support Closed-Loop Reverse Logistic Glocalized Solutions for Sustainability in Manufacturing, 2011.

[24] P. Vanegas, et al., "Information exchange requirements for cradle to cradle implementation in an industrial setting: EoL treatment of flat screen televisions," presented at the Life Cycle Management, Berlin, 2011. 